\title{
Educational potential of topic maps and learning objects for m-learning in the knowledge society
}

\author{
Potencial educativo dos mapas de tópicos e objetos de \\ aprendizagem para aprendizagem móvel na \\ sociedade do conhecimento
}

Miguel Ángel MARZAL'1

Silvia PEDRAZZI'

\begin{abstract}
The aim of the article is to present topic maps as a model for managing digital education content and learning objects for the design of digital teaching materials as the building blocks for an ideal educational model for the knowledge society: mlearning. We assess the educational benefits of topic maps using double entry tables for m-learning and propose criteria for determining the effectiveness of learning objects in mlearning. The findings reveal a need for further research for the effective management of educational content specific to mlearning, which is considered in pedagogical models such as in connectivism.
\end{abstract}

Keywords: Learning objects. Mobile communication services. Mobile learning. Topic maps.

\section{Resumo}

O objetivo deste trabalho é apresentar os mapas de tópicos como um modelo de representação e gestão de conteúdos educacionais digitais e objetos de aprendizagem para o desenvolvimento de materiais didáticos digitais baseado nos fundamentos da aprendizagem móvel, um modelo educativo de aprendizagem ideal numa sociedade do conhecimento. Para isso, avaliamos os benefícios educacionais dos mapas de tópicos usando o método de tabelas de dupla entrada para aprendizagem móvel e propomos critérios para avaliar os objetos de aprendizagem para medir a eficácia da aprendizagem móvel. Os resultados mostram a necessidade de futuras pesquisas para o gerenciamento efetivo do conteúdo educacional específico para a aprendizagem móvel, como aquele encontrado em modelos pedagógicos como o conectivismo.

Palavras-chave: Objetos de aprendizagem. Serviços de comunicação móveis. Aprendizagem móvel. Mapas de tópicos.

\section{Introduction}

A relevant working hypothesis for educators and designers of educational content is addressing how the concepts learned are stored, which leads us to consider the role of memory in the educational processes. So far, the most influential model distinguishes Sensory Memory (MS), Short-Term Memory (STM) and Long-Term Memory (LTM).

Scholars have classified long-term memory as declarative memory (also called explicit memory) and

\footnotetext{
1 Universidad Carlos III de Madrid, Facultad de Humanidades, Comunicación y Documentación, Departamento de Biblioteconomía y Documentación. Calle Madrid, 126, 28903, Getafe, España. Correspondencia a nombre de/Correspondence to: M.A. MARZAL.E-mail:<mmarzal@bib.uc3m.es>.

Received in 5/22/2014 and approved in 11/25/2014.
} 
non-declarative memory (or procedural memory). Declarative memory refers to memories that can be consciously recalled such as facts and knowledge. Declarative memory can be divided into two categories: episodic memory, which stores specific personal experiences, and semantic memory, which stores factual information. Semantic memories are those memories that store general factual knowledge that is independent of personal experience. This includes world knowledge, object knowledge, language knowledge, and conceptual priming.

Craik and Tulving (1975) showed that the ability to remember is connected to the depth of information processing in three levels: structural, phonetic and semantic. In fact, Psycholinguistic specialists are convinced that there is a specific mental lexicon able to arrange the shapes of words, spelling and other information.

Different models for information representation in our semantics memory have proposed. One of them, proposed by Collins and Loftus (1975) is useful for documentation. Its strength is based on the concept of semantic network, because for the authors the meaning of a sentence is explained by nodes and keywords connected to each other. This is more important when identifying strategies that the brain uses to remind, including association and mediation. Association consists of relating new information to concepts previously stored in the brain. Mediation requires a greater effort as one needs to transform something complex into something easier to remember through connections, associations, and organized structures, such as hierarchical taxonomies, so information can be easily organized, designed and reused. This research concerns the field of Learning Theories.

These premises guide the structure of the present study. We intend to discuss the most appropriate means for representing digital educational content; the best way for developing more effective models for information represention, which will trigger better memories and improved brain strategies that will transform information into knowledge. Standard topic maps are considered one of the best digital content management system for these purposes, particularly when considering the new frontier for learning in the knowledge society: mobile learning, a natural derivation of e-learning, but with a truly amazing educational potential (Pieri \& Diamantini, 2009). The objective is broad and ambitious, so we have chosen to address a key issue in the application of topic maps for the management of educational digital content: evaluation of mobile environments, as its capacity for knowledge representation has been proved (Freese \& Miller, 2000).

\section{Methods}

Models for representing resources for educational content

The possibility of using models of knowledge representation has been investigated in Psychology for several years. Mind maps and concept maps are probably the most widely used paradigms, together with those that have made topic maps possible.

A mental map is a diagram of basic notions of a topic, using shapes and colors, stating their relationships graphically, similar to how the brain makes these relationships to semantically associate an idea or concept. Building a mental map goes through several phases: a central concept is identified and placed in the center of an area; concepts and links are incorporated, creating a dynamic structure. Recently in the field of education, mental maps have been widely used for representing domain knowledge for its great advantage of providing an easy and intuitive reading even in very complex structures. Its strength lies in the use of logic for associative organization, which classifies and organizes in a reticulated way.

On the other hand, in accordance with Novak (2004), concept maps are arranged hierarchically, that is, the most comprehensive on top and the more specific at the bottom. Building a conceptual map for educational purposes involves determining knowledge domain with a clear definition of boundaries; identifying the functioning of educational objectives; identifying the main idea; identifying secondary concepts; clarification of any pre-requisite for knowledge; defining the relationships that bind concepts; identifying possible tertiary concepts (depth information); the evaluation of the map. 
Standard topic maps were developed in the nineties by a research group, the Davenport Group, whose main objective was to develop a standard for exchanging technical documentation software. The first product developed by this research group was called Sofabed, later redeveloped by the new research group called $\mathrm{CApH}$ from the Graphic Communications Association Research Institute (GCA4-RI) in 1993. With the revision of the Sofabed model, a new model called topic maps was developed and immediately accepted by International Organization for Standardization (ISO), which published the first official version of the ISO. Information technology: SGML applications topic maps, ISO/IEC 13250. In 2000, an independent consortium called TopicMaps.org was founded whose goal was to develop a new XML-based specification for topic maps to ensure greater dissemination and application of the standard on the web.

Topic Maps (TM) are therefore an ISO standard that defines a formal model and a way of representing knowledge in a standardized manner, as the very definition of the ISO states, "to make information easier to track". A great contribution to the TM has been the development of XML Topic Maps (XTM), which provide vocabulary and grammar based on XML for encoding and exchanging TM. The classic presentation of this model was the article by Pepper (2002), a pun referring to the Chinese word "tao", translated as road, route, and an acronym for Topic, Association and Occurrence. The basic elements of the model are as follows: topic is a symbol used within a TM to represent the subject; a subject can be anything whatsoever, an abstract concept, a name, about which anything whatsoever may be asserted by any means whatsoever; association identifies the relationship between two or more topics; occurence identifies instances of topics. All these TM elements became a powerful tool for creating semantic "clusters" of information, which could then be structured to generate knowledge (Ahmed, 2003).

\section{Topic maps as content management systems: Technical specifications and applications}

XTM 1.0 Specification: It was developed within the consortium TopicMaps.org and later included in the second edition of the 13250 standard in 2003. The system was developed over the years until the release of version 2.0 in 2007 (ISO/IEC IS, 13250-3: 2007), which includes a description of functionality (Garshol, 2006).

The basic requirements to develop the XTM system and create a syntax for the expression and exchange of Topic Maps are as follows: the system must be readable by humans; it must be simple and, therefore, the optional components should be minimized, if possible null; it must be compatible with the paradigm of the ISO 13250 standard; it should be designed quickly; it must support a variety of applications. The topicMap element is the root element of each XTM document and it can be used to develop a TM. For better illustration, below we define the basic elements of XTM.

The topic element is used to represent the topics: it has a mandatory and unique identifier; it also serves as a reference point for information about the topic element. The secondary elements of the topic element specify the identification, names and occurrences, whereas the association role is specified outside the topic element. These secondary elements are instanceOf, subjectldentity, baseName and occurrence. The sub-elements that compose the instanceOf and subjectldentity elements (topicRef; subjectIndicatorRef; resourceRef) can be defined as links and are repeated in other topic elements, maintaining the same function, to create the internal structure of TM or to link external resources.

The other key element is the baseName, which functions as an external representation for the user, that is, the base name of the topic and it consists of the following sub-elements: scope, baseNameString, variant. The scope element refers to the application and it can be compared to scope notes of thesauri, while the baseNameString element is where the characters of the base name are located. Finally the variant element can be repeatable and it has its own sub-elements: parameters (similar to the function of the scope element); variantName (similar to the function of the baseNameString element); variant (may appear as subelement of itself). The third sub-element of the topic is called occurence and it is defined by resourceRef and resourceData. Both are created to include metadata and thus enable links to various types of resources. 
Another sub-element of topicMap is association and it includes the following sub-elements: instanceOf (topicRef; subjectIndicatorRef); scope, (topicRef; subjectIndicatorRef; resourceRef); member, which includes rolespec (topicRef; subjectIndicatorRef) and topicRef (topicRef; subjectIndicatorRef; resourceRef). The roleSpec sub-element of member is important because it points to a topic that describes the role performed in the relationship. The last sub-element of topicMaps is called mergeMap, which allows the addition of new resources and it requires an application to run it.

Modifications in XTM 2.0 and 2.1: The reasons for the changes were mainly due to the new basic objective of XTM 2.0 that was to allow TM to be transferred from one place to another. The main changes in the XTM 2.0 version were: the URI of namespace was changed; the rolespec element was replaced by type element; the attribute version was added to the topicMap element; the variant element could not be nidified; the parameters element was replaced by the scope element; the mergeMap element no longer supported scope; the baseName element was replaced by the name element; the member element was replaced by the role element; the type element was incorporated into the name element; itemldentity, subjectLocator and subjectldentifier were merged; the variantName and subjectldentity elements were removed; the type element is now mandatory within occurence, association and role; the reifies attribute merged with some elements; the subjectIndicatorRef element was removed; the baseNameString element was replaced by value; XTM does not use XLink and XML base any longer; the datatype attribute merged with resourceData, which now supported markup embedded; the reifier attribute also merged.

On March 19, 2010, the ISO published a subsequent draft with new changes, which would define the XTM 2.1 version: the URI of namespace was changed; the version changed from 2.0 to 2.1; the reifer element merged; the subjectldentifierRef and subjectLocatorRef elements were reintroduced.

Applications of Topic Maps: In addition to all traditional semantic web areas of application, the literature shows that the applications of TM are numerous and continue to develop, particularly as follows:
- Library science and digital files. According to Iglesias and Stringer-Hye (2008), these were undoubtly the first fields that used TM application, as the TM developed by the Electronic library system at Electricité de France or the pioneer project at Stanford University, which has a built-in Java application written to retrieve documents by browsing through materials. <http:// highwire.stanford.edu/help/hbt/>.

- Cultural heritage, as in the Norwegian website Kulturnett.nos and the New Zealand website Electronic Text Centre.

- e-Goverment, management information systems in municipalities, as the website of the city of Bergen, accessible to city departments and management of administrative procedures through a structure based on TM <http://www.bouvet.no/BouvetWeb/>.

- e-Commerce to manage electronic catalogs of products, such as beverages and technologies, to provide support services to customers, as EPiServer <http:// www.episerver.com/e-commerce/>.

- Organization and development of semantically navigable portals and websites. One of the best known companies that has largerly contributed to the development ofTM has been Ontopia which, along with other companies such as Mondeca and InfoLoom, manages TopicMaps.org <http://www.topicmaps.org/> and is responsible for developing the XTM standards for web application. The great success of Ontopia has been the development of the Ontopia Topic Map Engine, a program that develops TM, allowing TM to create individual documents or sets of related documents, glossaries, taxonomies, etc. One of the most famous projects developed by Steve Pepper, founder and chief strategy officer of Ontopia, has been a TM on Italian opera, a Java-based application called Ontopia Knowledge Suite, and the other application called Ontopia Navigator Framework that uses a scripting language J2EE based on XML to develop thematic maps applied to the web. Two types ofTM have been developed: opera.xtm, a topic map using a browser called Omnigator for navigation and information in text mode, and TM Vizigator, a concept map.

- Distance Education. Among several projects in this area, Quality, Interoperability and Standards in 
E-learning (QUIS) deserves mention as the activities focus on quality, interoperability, reuse of content and development of standards. Another pioneering project is, Ontologies For Education (O4E), developed jointly by the University of Winston-Salem, the University of Pittsburgh and Saint-Petersburg State Polytechnic University, whose main objective is the collection and dissemination of resources for the application of ontologies with new educational perspectives. Finally, the BrainBank Learning program of Cerpus <http:// www.brainbank.no/brainbank/app/>, whose results have been discussed by Lavik and Nordeng (2004).

For the beneficial impact of Topic Maps for m-learning

As previsouly pointed out by Befring et al. (2008), technical specifications and applications in various fields allow TM to provide potential benefits for the management of educational content, especially for mobile devices. Thus, it is interesting to use the methodology of double-entry table to evaluate its efficiency. The purpose of this test is to compare the same information, the Italian opera, using two different sources:

1) The italian opera Topic Map opera.xtm that allows textual navigation <http://www.ontopia .net/ operamap/index.jsp>.

2) A simple electronic resource, i.e. a normal web page, which has the same arguments as TM and the same content on Italian opera <http://www.italianopera.org/>.

Two types of mobile devices, Samsung Galaxy smartphone and iPad, were used for the test. We have considered the factors related to Human-Computer interaction ( $\mathrm{HC}$ ) to analyze the interface, that is, what really interests the user, without going into the computer field of XTM and XML syntax. As the methodological experiment had been pre-tested, the research team defined as study group, a profesor and five graduate students, who were accustomed to digital learning environments.

First, to start the test, a double-entry table was built, consisting of a box system integrated with different variables displayed in rows and columns. From the table we developed different elements to obtain a value for each of the following: search; accessibility; interface/ usability. For greater detail, the systemic concept of doublé entry table enables the subdividision of these items in other sub-categories, using aspects covered in the Shneiderman and Plaisants's (2009) book Designing the user interface: Strategies for Effective humancomputer interaction:

a) Search. This category evaluates the search strategy using both resources and analyzes which could be the best for an average user to consult this information via a mobile device. It takes into account not only the search engines, but also the presentation of categories and results. The elements of the category are as follows:

- Search tools: thesauri, navigation maps, indexes, search engines.

- Presentation of categories: alphabetically, by date, documentary language.

- Presentation of results: alphabetical, by relevance, documentary language.

b) Accessibility. It analyzes the aspects related to functionality provided to users who may have disabilities. The elements of the category are as follows:

- Clear and simple documents.

- Clear navigation mechanisms.

- Ability to increase the size of elements.

c) Interface. It deals with the key challenges that allow the user to use all instruments that offer different resources and learn the content proposed in a clear and linear way. The elements of the category are as follows:

- Display elements: (1) menu (homogeneous, static elements, quick view); (2) links (color recognition, word recognition).

- Writing: spelling, language use, multilingualism

- Graphics: up to three fonts, four colors, four sizes, two levels of intensity.

- Spatial organization: reading sequence, alignment, highlights.

Once the double entry table was established and completed, each element had to be given a value: $1=$ equal in importance; 5 = far more important; $10=$ very important; $1 / 5$ or $0.2=$ somewhat less important; $1 / 10$ or $0.5=$ very unimportant. 
To compare the two different resources, the results of the base matrix were correlated. The values of each element were considered taking into account the minimum knowledge of a user of high-tech mobile devices. The Tables 1, 2 and 3 show the scores assigned to each item, comparing the two resources to perform the analysis.

The resource that received the highest score for a keyword search was the Topic Map xtm (37.2 points) when compared to the website (24). The two resources have a section to find information via the classic search bar, like any other search engine. While the website uses Google custom search engine, the TM has its search system and presentation of results. One of the most important aspects of a TM is being able to search for information in a simple and orderly manner, therefore its high rating is not surprising.

For accessibility, TM xtm also received the highest score (25.2), followed by the website (3.6). Accessibility is very important when developing a learning resource and even more if the support of this resource can vary, as in the case of m-learning, we must consider that not only the device, but also the content, must be adapted to the user.

Due to its interface, the resourse that received the highest score was the TM xtm (86.8), followed by the website (66.2).

The main conclusion from this brief analysis was that the documents created and organized by the TM method demanded a series of logical connections that can support distance learning of any type of content. The TM is an excellent tool for sharing and integrating content in technological environments. Moreover, the TM adapts well to the visual mapping software VIzigator, providing a more intuitive view of information. However, the learning environments must be investigated based on pedagogical theories that will generate relevant content and suitable teaching materials according to the new technologies. As these training materials have their own characteristics and design (Sharples et al., 2002), it is important to understand the educational theories and teaching strategies, particulary about evaluation of

Table 1. Double entry table of the Search element.

\begin{tabular}{|c|c|c|c|c|c|}
\hline \multicolumn{3}{|c|}{ Indicator } & \multirow{2}{*}{$\frac{\text { Weight }}{2}$} & \multirow{2}{*}{$\frac{\text { Topic Maps }}{2}$} & \multirow{2}{*}{$\frac{\text { Website }}{0}$} \\
\hline & Search tools & Thesauri & & & \\
\hline & & Indices & 2 & 2 & 2 \\
\hline & & Engine & 2 & 2 & 2 \\
\hline & & Alphabetically & 5.2 & 5.2 & 0 \\
\hline \multirow[t]{5}{*}{ Search } & Categories displayed & By relevance & 10 & 10 & 10 \\
\hline & & By document language & 0.4 & 0.4 & 0 \\
\hline & & Alphabetically & 0.4 & 0.4 & 0 \\
\hline & Results displayed & By relevance & 10 & 10 & 10 \\
\hline & & By category spec. & 5.2 & 5.2 & 0 \\
\hline Total & & & 37.2 & 37.2 & 24 \\
\hline
\end{tabular}

Source: Preparation by the authors (2014).

Table 2. Double entry table of the Accessibility element.

\begin{tabular}{llccc}
\hline & \multicolumn{1}{c}{ Indicator } & Weight & Topic maps & Website \\
\hline \multirow{4}{*}{ Accessibility } & Document clarity and simplicity & 8.4 & 8.4 & 0 \\
& Navigation mechanism clarity & 13.2 & 13.2 & 0 \\
& Element size adjustability & 3.6 & 3.6 & 3.6 \\
\hline Total & & 25.2 & 25.2 & 3.6 \\
\hline
\end{tabular}

Source: Preparation by the authors (2014). 
Table 3. Double entry table of the Interface element.

\begin{tabular}{|c|c|c|c|c|c|c|}
\hline \multicolumn{4}{|c|}{ Indicator } & \multirow{2}{*}{$\frac{\text { Weight }}{16}$} & \multirow{2}{*}{$\frac{\text { Topic maps }}{16}$} & \multirow{2}{*}{$\frac{\text { Website }}{16}$} \\
\hline \multirow{16}{*}{ Interface } & \multirow{6}{*}{ Elements displayed } & menu & Consistency & & & \\
\hline & & \multirow{5}{*}{ links } & Static elements & 5.6 & 0 & 0 \\
\hline & & & Speedy display & 10.4 & 10.4 & 10.4 \\
\hline & & & Colour recognition & 6 & 6 & 0 \\
\hline & & & Text recognition & 6 & 0 & 0 \\
\hline & & & Literal sense & 0.4 & 0.4 & 0.4 \\
\hline & \multirow{3}{*}{ Writing } & \multicolumn{2}{|c|}{ Spelling and grammar } & 6 & 6 & 6 \\
\hline & & \multicolumn{2}{|c|}{ Proper use of language } & 16 & 16 & 16 \\
\hline & & \multicolumn{2}{|c|}{ Language offering } & 6 & 0 & 6 \\
\hline & \multirow{4}{*}{ Graphics } & \multicolumn{2}{|c|}{ Up to three fonts } & 2.2 & 2.2 & 0 \\
\hline & & \multicolumn{2}{|c|}{ Up to four colours } & 11 & 11 & 0 \\
\hline & & \multicolumn{2}{|c|}{ Up to four sizes } & 7 & 7 & 0 \\
\hline & & \multicolumn{2}{|c|}{ Up to two levels of intensity } & 1.4 & 1.4 & 1.4 \\
\hline & & \multicolumn{2}{|c|}{ Reading sequence } & 10 & 10 & 10 \\
\hline & Spatial organisation & \multicolumn{2}{|c|}{ Alignment } & 0.4 & 0.4 & 0 \\
\hline & & \multicolumn{2}{|c|}{ Contrast } & 5.2 & 0 & 0 \\
\hline \multicolumn{4}{|l|}{ Total } & 109.6 & 86.8 & 66.2 \\
\hline
\end{tabular}

Source: Preparation by the authors (2014)

instructional design principles and methodologies (Berking et al., 2012), compendium of experiences on conceptualization, and definition of m-learning (El-Hussein \& Cronje, 2010).

\section{Results}

Requirements of digital educational resources and content design for m-learning

It is important to understand the tendencies (Quinn, 2011) and best practices (Ally \& Tsinakos, 2014) of this new teaching method, mobile learning, which is transforming the educational scenario (West, 2012) through a specific pedagogical framework for the effective application of educational strategies (Park, 2011). The digital revolution has brought about a major transformation in educational practices, such as the emergence of informal learning. However, it must be pointed out that specific and suitable teaching materials, which must be well characterized and organized, must be developed for this new learning environment (McGreal, 2007). Naturally, this new educational model creates a new kind of documentary collection in digital educational libraries (Humphries, 2012) that require proper format (Stead, 2012) and interesting projects (Chapman et al., 2012), because mobile devices are a new professional tool for librarians (Arroyo-Vázquez, 2013).

Teaching methods are not limited to the transmission of formal knowledge, but the trend is to cooperate, create, view and edit learning contents at anytime and on any device. George Siemens, famous theorist of digital education, proposes the adoption of the term connectivism (Siemens, 2004) to refer to the new way of learning, characteristic of the digital era, which is based on the inclusion of technology in cognitive processes and learning. Connectivism is based on the idea that the individual is continually acquiring new information through "non-human" devices and the learning process takes place through the connection of nodes and specialized sources within a large grid system in which technology plays a fundamental role in the distribution of competence, identity and knowledge. As Herrington et al. (2009) points out, an appropriate pedagogical framework, as discussed above, requires the development of teaching applications that are closely related to the Technologies of Information and Communication (TIC).

This explains the great potential of m-learning, whose effectiveness however requires some specific competences and a proper educational framework 
(Prensky, 2004). In fact, although the subjects within the network preserve their personal identity, they are committed to compress the identity on several occasions to expand their opportunities for interaction. The effectiveness of m-learning, however, demands quality content learning material specifically designed for this new type of education, a specific model for instructional design. In this sense, m-learning has some peculiarities that need to be considered such as the high degree of agreement on the main requirements that the educational resources for distance learning must comply to, within the concept of Learning Objects (LO), which have proven to be effective in learning and furthering knowledge (Mestre, 2010).

Modularity means the gradual division of contents of knowledge into multiple parts and levels to facilitate the process of sequencing and organization with the purpose of providing better understanding and thereby increasing reusability of educational resources in different contexts. Self-consistency is closely related to reuse since an object that is truly reusable should not depend on other objects (according to the principle of selfsufficiency). Reuse largely depends on the ability to easily retrieve the object, i.e., the ability to search and download the object into a specific repository. To maximize availability, it is essential that the resource be previously catalogued with an appropriate metadata description (Calzada Prado, 2010). Reuse is closely related to portability and interoperability. These concepts are related to the independence of the object from the operating system used and the applications that use the object. In general, the concept of interoperability refers to the ability of the applications and computer systems to cooperate and exchange information and services with other systems or applications with reliability and optimization of resources. Accessibility is closely related to usability, as the man-machine interaction creates a relationship of communication and exchange of information through an interface. Thus, it plays a decisive role in the process and has the important task of helping the user build a mental model of the system and learning objects. Personalization of content is one of the objectives of current m-learning research, but there is no satisfactory answer up to the present. The implementation of TM models to create and organize m-learning structures could greatly help the development of this aspect regarding the structuring, management, and presentation of content.

The design of educational content in the $\mathrm{m}$ learning context, therefore, is to organize topics, key concepts, and possible ways of knowledge that can define the exploration of this domain. Over the years, several models have been proposed to formalize or provide best practices. Some of these models, dating back to the eighties, were design-inspired on the software engineering approach called 'cascade' (Vivanet, 2009), as it establishes the planning of learning content and materials in a way that the sequence of steps allows the structuring and analysis of the requirements, design, development, testing, integration and maintenance.

However, these models have been criticized and proposals of its own review of the debate on software engineering, emerging paradigm "spiral". It is characterized by its orientation to the rapid production of prototypes that can be submitted to validation by the end user and, therefore, modified in an extremely flexible way. In current design models of content, approaches that endeavor to integrate m-learning solutions through knowledge management have been designed with the purpose of creating strategies for identifying, collecting, developing and preserving knowledge, which may be useful to new educational models.

One of the most widely used models in the field of Instructional Content Design (IDS) is Analysis, Design, Development, Implementation and Evaluation (ADDIE) models. The ADDIE model has five distinct stages that offer a dynamic and flexible guide to build effective instruments to support education. The model seeks to receive continuous or formative feedback through the following five stages:

- Analysis stage: the educational objectives, learning environments and knowledge are established, and the student's skills are identified. Some basic questions are asked: Who are the recipients and which are their characteristics? In which kind of learning environment is learning developed? What are the restrictions? Which pedagogical considerations must be considered?

- Design stage: it is concerned with establishing the learning objectives, assessment instruments, exercises, 
content and analysis of materials around an educational project. It must be systematic and specific, with an orderly method of identification, development and evaluation of planned strategies geared towards achieving project outcomes, together with a detailed plan of the instructional design. The basic material is: project documentation, strategic design, technical and visual; implementing educational strategies consistent with the studied areas (cognitive, affective and psychomotor); creating a storyboard; design use interfaces and user experiences; creating a paradigm.

- Development stage: this stage builds and assembles the contents that were created in the design stage. Programmers work to develop and/or integrate new technological solutions for m-learning application and run different verification tests.

- Implementation stage: it consists of the training of facilitators of students. Training should cover the curriculum, learning outcomes, delivery method, and testing procedures. Preparation includes preparing students for the use of new tools (software or hardware).

- Evaluation stage: it consists of two parts: formative evaluation is present at every stage of the ADDIE process, while the specific stage is to analyze Learning Objects ( $\mathrm{LO}$ ) through various criteria depending on the type of project developed.

A more recent model design for distance learning systems, cited by many researchers in the field of distance education, is implicit in the ISO/IEC 19796-1:2005, Information Technology Learning, Education And Training (ITLET) Quality management, assurance and metrics, Part 1: General approach standard. An initiative created with the intention of providing a general reference system under which, in more analytical terms, the quality of distance education systems are described. The standard includes the following steps (Adorni et al., 2008): Needs Analysis; Framework Analysis; Conception/Design; Development/Production; Implementation; Learning Process; Evaluation/Optimization.

Undoubtedly the most complex stage in content design is the Conception/Design which, in turn, involves a number of steps, such as: Learning Objectives; concept for contents; didactical concepts/methods; roles and activities; organizational concept; technical concept; concept for media and interaction design; media concept; communication concept; concept for testing and evaluation; concept for maintenance (Stracke, 2010).

One of the most frequently mentioned models in the literature was the one developed by Cisco Systems Inc., leader in networking technologies, that proposed the notion of Reusable Learning Object (RLO) to indicate a minimum reusable instructional objective. The model is based on a hierarchical architecture of five levels (course, module, lesson, topic, subtopic). Each course must correspond to a single overall educational objective that each student must achieve (Dawson, 2009).

A proposal from a theoretical model for digitaleducational content

An Italian research group at the University of Genoa, headed by Giuliano Vivanet, and other researchers from the international scientific community, have developed an interesting model for projects formlearning. The model is interesting because it focuses on the combination of teaching techniques for distance education and Topic Maps tool for the management and development of educational content as a means for implementing new semantic models. In fact, the author already discusses future modifications, such as modifying the vocabulary of relationships between the topic and developing semantic links to make the meaning of relationships explicit.

The model uses Bloom's taxonomy (Bloom, 1956). The studies of Mager (1962), expert on human performance improvement, have largely contributed to the model by clarifying the concept of "learning objective", which is defined as a description of actions that learners must be able to do to demonstrate competence. Another key contribution is that of Raso (2007) who identifies three main areas on the relevance of the objectives: the cognitive, affective and psychomotor area.

One of the main characteristics of the model is its focal point directed towards the learner, which in fact is the starting point as it analyzes the characteristics of the subject to which it is addressed. Several methods (direct and indirect) can be used to conduct the analysis, taking into account the cognitive, affective and relational 
characteristics of the subject in order to identify their learning needs. There are several rules to describe the profile of a student, although the most commonly used are the IEEE Public and Private Information (PAPI) and the IMS Learner Information Package (LIP).

The goal of the IEEE is to provide syntax and semantics of a suitable model to the student, including knowledge, learning styles, abilities, data and personal information. The great innovation of IEEE is the logical classification of the data and the extension mechanism to allow customizations, considering aspects such as cultural and institutional conventions and security management. Furthermore, IMS Learner Information Package uses XML language, through which the information of students is described by using 11 levels (identification, qlc, accesibility, activity, goal, competency, interest, transcript, affliation, Securitykey and relationship), which may be modified at any time since the model is designed to be extensible and flexible.

Once the group characteristics are established to which the educational content is directed, one must determine the Objetive element, which, as its name suggests, represents the ultimate goal of learning associated to the SubjectMatter (educational intervention). Then it becomes possible to specify any relationships among them (through the relationship isRequirementOf). Thus, a logical and chronological system of educational objectives are created, explained through the identification of a UnitOfLearning, a learning unit derived from the fragmentation of the SubjectMatter.

Another significant feature relevant to m-learning is: the ability to choose the associations of educational resources. In fact, educational resources can be associated to the SubjectMatter and UnitOfLearning nodes, or as elements with their own resource. This choice is particularly important because it allows the 'manipulation' of part of the model that has to do with the teacher's criteria.

Once the objectives and themes of the training contents are defined, the topic is identified, with the purpose of expressing the key concepts of each learning unit. The author defines two different classes to the topic (TopicType) PrimaryTopic or SecondaryTopic, which allow the identification of different concepts. In fact, the prerequisites of the learning unit are identified with the
PrimaryTopic class, while the concepts presented during the development of the learning unit and associated to specific educational resources are identified with the SecondaryTopic class. These two possibilities are particularly relevant in a distance education model in which most of the information that could be provided by the teacher in person (as in the case of the prerequisites of the learning unit) has to be placed virtually.

Finally, Effort and UnitOfLearningEffort elements allow the introduction of an indicator of effort for each subject. This element allows the evaluation of the course in terms of 'credits' or it can simply specify the time required to learn certain concepts, which varies according to the student profile.

\section{Discussion}

\section{The evaluation of digital content for m-learning}

It seems useful to know the framework and application of m-learning, as it provides requirements for an evaluation (Motiwalla, 2007) based on assessment methodologies specifically related to the attributes of $m$ learning (Traxler, 2007). Many factors must be considered when evaluating $\mathrm{LO}$, both during the course and postproduction of LO, particularly students' perceptions and experiences (Kim et al., 2013). In any case, the assessment of $\mathrm{LO}$ is an important element that affects all processes that form the m-learning model. The international scientific literature provides assessment tools (Hernández et al., 2012), several quality models and approaches that can be applied to LO, but few specific valid proposals for LO in m-learning contexts.

According to Vidal et al. (2008), from the point of view of production, the quality of a LO can be measured differently if we consider it as product or as process. If LO is considered a product, the quality can be measured directly or indirectly: (a) through a set of desirable characteristics; (b) by its internal structure; (c) its pedagogical potential for a given context or new contexts; (d) the quality of the metadata from which clarity or consistency of metadata content can be measured. 
It seems necessary, from the analysis of the international literature, to identify several LO assessment models that have been developed and improved by the massive use of distance education methodologies, as shown in the following Table 4:

The standards listed in the table have common variables:

- Pegagogical variables.

- Technological variables.

- Content variables.

However, to assess LO in m-learning we need to consider it as well as the difficulties in the learning environment through mobile devices, such as those arising from the operation of digital communication channels, the quality of technological and educational information, and methodological and organizational design of education (Torres Toro \& Carrillo Ortega, 2003) (Table 5).
It seems useful to propose, therefore, four areas of analysis to assess the overall context of an m-learning application:

1) Area of technical quality (Torres Toro \& Carrillo Ortega, 2003).

2) Area of cognitive ergonomics (author's contribution).

3) Area of organizational quality (Torres Toro \& Carrillo Ortega, 2003).

4) Area of cognitive and constructivist principles (Honey \& Mumford, 2000).

The first area identified by Torres Toro and Ortega Carrillo (2003) was technical quality. It refers to the technical characteristics of the distance education platform, which should ensure stability and robustness in the management processes of teaching. It is certainly a key area in m-learning platforms, as the technological aspect of this type of education is a fundamental element.

Table 4. Quality criteria for Learning Objects (LO).

\begin{tabular}{|c|c|}
\hline Model & Characteristics \\
\hline $\begin{array}{l}\text { Reeves pedagogical evaluation } \\
\text { (Reeves, 1997) }\end{array}$ & $\begin{array}{l}\text { Consists of } 14 \text { pedagogical dimensions based on learning concepts and theories, i.e.: } \\
\text { epistemology, pedagogical philosophy, psychological support, objectiveorientation, experimental } \\
\text { validity, instructor's role, programme flexibility, adaptation to individual differences, learning } \\
\text { control, user activities, cooperative learning and cultural sensitivity. }\end{array}$ \\
\hline $\begin{array}{l}\text { LORI (Learning Object Review Instrument) } \\
\text { (Nesbit et al., 2003) }\end{array}$ & $\begin{array}{l}\text { Furnishes an evaluation framework for LO based on the analysis of nine items, scored on a } \\
\text { five-tier scale. The nine dimensions evaluated are: content quality, learning goal alignment, } \\
\text { feedback and adaptation, motivation, presentation design, interaction usability, accessibility, } \\
\text { reusability, standards compliance. }\end{array}$ \\
\hline MERLOT (Vargo, 2003) & $\begin{array}{l}\text { Constitutes a learning object repository (LOR) that evaluates the quality of the learning } \\
\text { objects stored and ranks the objects evaluated on the grounds of three criteria: content } \\
\text { quality, potential effectiveness and convenience of use. }\end{array}$ \\
\hline $\begin{array}{l}\text { Learning Objects evaluation criteria } \\
\text { (Morales, 2008) }\end{array}$ & $\begin{array}{l}\text { These criteria are grouped under four headings: psychopedagogical, didactic-curricular, } \\
\text { technical-aesthetic and functional. The authors propose a framework for the comprehensive } \\
\text { evaluation of LO on the grounds of these criteria. }\end{array}$ \\
\hline $\begin{array}{l}\text { Quality criteria } \\
\text { (Paulsson, 2006) }\end{array}$ & $\begin{array}{l}\text { Reviews the } L O \text { available in repositories, focusing on four properties: architecture, pedagogical } \\
\text { contextualisation, use of standards and extent to which they are decomposable or composable. } \\
\text { The study concludes with a proposal for six areas of action that could help establish quality } \\
\text { criteria: narrower definition of } L O, \text { mapping taxonomy, more extensivestandards, bestpractice in } \\
\text { use of existing standards, architectural models, separation of pedagogy from the supporting } \\
\text { technology. }\end{array}$ \\
\hline $\begin{array}{l}\text { Elements determining quality } \\
\text { (Velázquez, 2007) }\end{array}$ & $\begin{array}{l}\text { The elements that determine LO quality are: technological, pedagogical, content and aesthetic, } \\
\text { and ergonomic. The authors propose tools for measuring LO quality in terms of the above } \\
\text { dimensions. }\end{array}$ \\
\hline
\end{tabular}

Source: Brito Gonzalo (2009). 
Table 5. Mobile device-related learning difficulties.

\begin{tabular}{|c|c|}
\hline Category of difficulty & Description \\
\hline Related to digital communication channels & $\begin{array}{l}\text { - Slow transmission of information, particularly in the real-time reception of compressed } \\
\text { multi-media documents. } \\
\text { - Unexpected interruption of the communication. } \\
\text { - High cost. } \\
\text { - Delay in real-time audio-visual communication. } \\
\text { - Frequent server outages. }\end{array}$ \\
\hline $\begin{array}{l}\text { Related to the technological-educational } \\
\text { quality of the information }\end{array}$ & $\begin{array}{l}\text { - Obsession for the generation of literary content. } \\
\text { - Neglect for the aesthetic quality of the graphic and multimedia design. } \\
\text { - Undue proportion of linear text. } \\
\text { - Scant creativity and neglect of semantics in visual texts and especially in photographs. } \\
\text { - Incorrect approach to diagrams and graphics. } \\
\text { - Existence of communications noise (flawed figure-background interaction, inappropriate } \\
\text { vocabulary, fuzzy visual texts, poorly focused multimedia or faulty sound reception, etc.). }\end{array}$ \\
\hline $\begin{array}{l}\text { Related to the design of educational } \\
\text { methodology and organisation }\end{array}$ & $\begin{array}{l}\text { - Obsession with conveyance of content. } \\
\text { - Neglect for objectives relating to social and ethical citizenship training. } \\
\text { - Tendency to use conductivist methodologies. } \\
\text { - Obsession with efficient knowledge acquisition. } \\
\text { - Tendency to evaluate results often omitting the analysis of knowledge construction } \\
\text { processes. } \\
\text { - Over-use of automatic monitoring, evaluation and tutoring. } \\
\text { - Omission in the design of instructional strategies based on "many to many" } \\
\text { intercommunication intended to encourage the creation of shared knowledge. }\end{array}$ \\
\hline
\end{tabular}

Source: Torres Toro and Carrillo Ortega (2003).

The variables to be analyzed could be:

- The technological infrastructure in general, but especially its accessibility and complexity.

- If platforms were developed using an open-code software, the cost of access and maintenance.

- The level of expertise that is required to use it.

- The quality of security control systems.

- The quality of access systems for processes and materials.

The second area is one of the most important, not previously mentioned in any of the m-learning projects analyzed, is as follows: the quality of cognitive ergonomics. As defined by Cañas (2006), cognitive ergonomics studies human activities related to information processing and knowledge that influence or are influenced by objects. In order to promote the usability of the product or its surroundings, the most important objetives of mobile devices, according to Cañas, are:

- Reduce the cognitive effort and errors when using the product (less learning, representational transformations, memories of intermediate stages when solving problems and performing tasks).

- Improve performance, productivity and efficiency in learning tasks.

- Improve security.

- Improve comfort.

From these objectives, the following variables must be analyzed:

- Heuristic evaluation of the interface of the mlearning application:

- Mental load (cognitive workload).

- Specific variables according to some existing models (Han et al., 2008).

Thirdly, it is convenient to consider the quality of the organizational and creative development of the teaching and learning processes. From this perspective, as suggested by Torres Toro and Carrillo Ortega (2003, p.4), we need to assess:

- The flexibility to outline teaching and learning strategies (supported by strategies of cognitive, 
constructivist and/or behavioral nature, or a combination of these).

- The ability to adapt and use it in other educational settings (informal education, virtual learning communities, training of professional groups, etc.).

- Versatility in designing and implementing a support and reinforcement system for students, according to the different learning rates and curricular options.

- Offer tools for the design and management of e-learning programs, easy to use and with good creative possibilities.

- Ability to organize content using indices and concept maps

- Ability to create automatic and/or manual glossaries of terms related to the learning units and cultural diversity of the participants.

Finally, it is especially important to study the cognitivist and constructivist principles that can help create a good design of educational processes for $\mathrm{m}$ learning. The fundamental aspects in creating $\mathrm{LO}$ for $\mathrm{m}$ learning are the cognitive principles, principles of active learning, significance oflearning, organizational autonomy, and cognitive balance.

- Active learning is the basis for the development of critical thinking skills and creative thinking through the interaction of concepts, instances and relations. The concept of active learning can be related to the philosophy of the Topic Maps model, thanks to its specific conceptual structure, which has proven to be a model of educational effectiveness.

- The significance of learning: Ausubel defined it as meaningful learning based on prior use of students' knowledge to build new learning. A strategy to support meaningful learning is the visual representation of concepts, objects or situations through schemes for knowledge representation (indicating concepts, propositions and explanations). It is a theory that is also in agreement with the philosophy of the Topic Maps model, particularly its ability to graphically visualize concepts and their relationships.

- The organizational autonomy and cognitive balance that consists of content and organization of virtual learning materials, which promotes independent learning,'learning to learn'and'learn to express what has been learned' using codes and languages from information technologies (Torres Toro \& Carrillo Ortega, 2003).

All these principles can be useful when facing the initial development of a learning project, but not specifically dealing with distance education projects such as m-learning. The scientific literature reviewed so far lacks information, but researchers in the field of distance education have increasingly more interest in the development of specific standards for m-learning platforms. In fact, the topics discussed at the Twelfth International Conference on m-learning "mLearn 2013" in Doha in October <http://webit.cna-qatar.edu.qa/ mlearn2013/> particularly focused on the development of theories, models and ethics for mobile learning, and the interactive design and usability of m-learning platforms. These same issues were discussed during the conference "MLearnCon 2013", organized in California in June, <http://www.elearningguild.com/mLearnCon/ content/2702/mlearncon-2013-conference--expo--home/> and in the "MOBllearn Asia 2013", one of the most important initiatives in Asia, organized in Singapore in October 2013 (https://ashleytan.wordpress.com/2013/ 10/02/my-mobilearn-asia-2013-presentation/). The quality of the standards for m-learning platforms have become the center of a great debate, which should lead to new initiatives and reflection on the future development of this research topic.

\section{Conclusion}

The arguments developed in the present study provide clear results for the effective development of $m$ learning as an essential field for lifelong learning and optimization of the process of knowledge dissemination and innovation on the web, which is essential for progress in the knowledge society.

Mobile learning and its instruments must guide the development towards optimizing learning outcomes by creating a space of convergence between the human 'mindset' and "associative structure" of the digital content on the Web. Connectivism may be an appropriate educational framework, as it: includes the Serendipity 
within learning networks (the curiosity for learning instead of chance), provides socialization focused on the object (social networking), sees the conception of the mind as a network, but especially the ecologies of learning (derived from information ecology and ecology of knowledge) which, according to connectivism, is a living organism of the network, a structured process consisting of nodes and connectors. The ecology of learning has the following principles: primacy of social networks of people (not technology); primacy of learning exchanges of knowledge and relationships; competition in cooperation; learning through knowledge nodes; flows of knowledge.

The TM specifications, news, and above all, its applications are considered as an ideal tool for developing m-learning within the parameters of connectivism. Its elements, use and potential effectively support the transfer of digital information into knowledge, as it is capable of managing content, generating a fundamental "map" of links, hypertext, hyperlinks and connectors, as the elements provide a solid gramatical base for digital discourse within the educational objectives of m-learning.

The properties and nature of m-learning, supported by TM, determine which "digital learning materials' meet the specific visible characteristics in LO. However, the educational suitability of LO on mobile devices through the management of TM require tools that demonstrate its educational benefits in m-learning. There have been successful experiences such as CISCO System Inc. and, more specifically, the Vivanet model. However, the topics of scientific and technical events around m-learning during 2013 show that research on instructional design of educational content in m-learning is a strong and novel research trend. The methodological experiences of the present study go in that direction.

The educational effectiveness of $\mathrm{LO}$ in m-learning, as a previously discussed, turns the assessment of $\mathrm{LO}$ in mobile environments into another key research topic in m-learning as it is an ideal educational model in the knowledge society. The need to evaluate digital content and $\mathrm{LO}$ is promoting initiatives on measuring the impact of information and informational ownership that involves the development of specific assessment tools. This raises the need to determine the appropriate assessment instruments: (a) 'evaluative survey' a pool of questions designed in accordance with statistical methods that (quantitatively or qualitatively) measure opinion, perception of phenomena, or the value of characteristics on a given topic, a tool for skills that relies on a "checklist" and its criteria model; (b) questionnaires to measure skills whose interpretation of data is closely related to a set of indicators, which are projected in templates assessable criteria, statistically formulated and update the questionnaires.

\section{References}

Adorni, G. et al. Elearning, personalizzazione, strategie e tecniche didattiche: definizione di sottoprocessi per una progettazione didattica in qualità. Atti Didamatica, Toronto, 2008. Disponibili in: <http://didamatica2008.di.uniba.it/> Accesso: 19 magg. 2014.

Ahmed, H. Introducing topic maps: A powerful, subjectoriented approach to structuring sets of information. XMLJournal, 2003. Available from: <http://kalahmed.ulitzer.com/ latest/articles>. Cited: May 8, 2014.

Ally, M.; Tsinakos, A. (Ed.). Increasing access through mobile learning. Vancouver: Commonwealth of Learning and Athabasca University, 2014.

Arroyo-Vázquez, N. Bibliotecario, trae tu propio smartphone a la biblioteca. Anuario Thinkepi, v.7, p.89-90, 2013.

Befring, E. et al. Topping mapping the national curriculum. In: International Topic Maps Users Conference, 2, 2008, Oslo. Towards the vision of Subject-Centric. Oslo: Computing, 2008.

Available from: <http://www.topicmaps.com/tmc/ presentation.jsp? conf $=$ TM2008\&id=TM2008 $>$. Cited: May 19, 2014.

Berking, P. et al. Mobile Learning: Not just another delivary method. 2012. In: The Interservice/Industry Training, Simulation \& Education Conference, 2012, Orlando. Proceedings electronics... Orlando: National Training Systems Association, 2012. Available from: <http://www.adlnet.gov/ wp-content/uploads/2012/12/12079.pdf>. Access: May 19, 2014.

Bloom, B.S. Taxonomy of educational objectives, the classification of educational goals. Longman: Group United Kingdom, 1956.

Brito Gonzalo, J. Objetos de aprendizajey educación: ¿Promesas o posibilidades reales? Córdoba: Universidad Nacional de Córdoba, 2009. Disponible en: <http://ocw.unc.edu.ar/proed/ objetos-de-aprendizaje-y-educacion-bfpromesas-o/ actividades-y-mat eriales/modulo-5>. Acceso en: 19 mayo 2014. 
Calzada Prado, F.J. Repositorios, bibliotecas digitales y CRAl: los objetos de aprendizaje en la Educación Superior. Buenos Aires: Alfagrama, 2010.

Cañas, J.J. Personas y máquinas: el diseño de su interacción desde la ergonomía cognitiva. Madrid: Pirámide, 2006.

Chapman, J. et al. The Suma Project: An open-source, mobile tool enabling observational data collection ans analysis. In: Library Assessment Conference, 2012. Charlottesville. Available from: <http://libraryassessment.org/bm doc/chapmanjoyce-2012-poster.pdf>. Cited: May 19, 2014

Collins, A.; Loftus, E. A spreading-activation theory of semantic processing. Psychological Review, v.82, n.6, p.407-428, 1975.

Craik, F.I.M.; Tulving, E. Depth of processing and the retention of words in episodic memory. Journal of Experimental Psychology: General, v.104, n.3, p.268-294, 1975

Dawson, D., Assembly of RLOs. 2009. Available from: <http:// uwf.edu/ddawson/d3net/research/rlo_assembly.htm>.Cited: May 19, 2014.

El-Hussein, M.O.M.; Cronje, J.C. Defining mobile learning in the higher education landscape. Educational Technology \& Society, v.13, n.3, p.12-21, 2010

Freese, E.; Miller, E.J. Using topic maps for the representation, management \& discovery of knowledge. In: Conference XML: Europe 2000. 2000, Paris. Proceedings electronics... Paris: Garden Centre Association, 2000. Available from: <http:// www.gca.org/papers/xmleurope2000/papers/s22-01.html>. Cited: May 19, 2014

Garshol, L.M. An introduction to XTM 2.0. 2006. Available from: <http://www.garshol.priv.no/blog/82.html>. Cited: May 19, 2014.

Han, P. et al. Exposure and support of latent social networks among learning object repository users. Journal of Universal Computer Science, v.14, n.10, 2008. Available from: <http:// www.lon-capa.org/papers/jucs_14_10_1717_1738_han. pdf >. Cited: May 19, 2014

Hernández, Y.et al. Instrumento de evaluación para determinar la calidad de los objetos de aprendizaje combinados abiertos de tipo práctica. Latin American Community on Learning Objects, v.3, n.1,2012. Disponible en: <http://laclo.org/papers/ index.php/laclo/article/view/20>. Acceso en: 19 mayo 2014.

Herrington, J. et al. New technologies, new pedagogies: Mobile learning in higher education. Wollongong: University of Wollongong, 2009.

Honey, P.; Mumford, A. The learning styles helper's guide. Maidenhead: Peter Honey Publications, 2000.

Humphries, A. A dose of (augmented) reality: Exploring possible uses within a library setting. 2012. Available from: <http://mlibraries.jiscinvolve.org/wp/2012/12/12/a-dose-ofaugmented-reality-exploring-possible-uses-within-a-librarysetting/>. Cited: May 19, 2014.

Iglesias, E.; Stringer-Hye, S. Topic Maps and the ILS: An undelivered promise. Library Hi Tech, v.26, n.1, p.12-18, 2008.

Kim, D. et al. Students' perceptions and experiences of mobile learning. Language Learning \& Technology, v.17, n.3, p.52-73, 2013.
Lavik, S.; Nordeng, T.W. Brain bank learning building personal topic maps as a strategy for learning. In: XML Conference and Exposition. Washington, 2004. Available from: $<$ http:// cerpus.com/content/actual/publications/bb-aslearning-strategy/bb-as-learning-strategy.html>. Cited: May 19, 2014.

Mager, R.F. Preparing objectives for programmed instruction. Belmont: Fearon Publishers, 1962

Mestre, L.S. Matching up learning styles with learning objects: What's effective? Journal of Library Administration, v.50, n.7-8, p.808-829, 2010.

McGreal, R. A typology of learning object repositories. Auspace, v.9,2007. Available from: <http://hdl.handle.net/2149/1078>. Cited: May 19, 2014.

Motiwalla, L.F. Mobile Learning: A framework and evaluation, Computers \& Education, v.49, p.581-596, 2007.

Novak, J.D. Los mapas conceptuales: teoría, metodología, tecnología. In: Canas, A.J.; Fermín González, M. (Ed.). In: Conferencia Internacional sobre Mapas Conceptuales, 1., 2004, Pamplona.Actas... Pamplona: Universidad Pública de Navarra, 2004. p.1-38.

Park, Y. A pedagogical framework for mobile learning: Categorizing educational applications of mobile technologies into four types. International Review of Research in Open and Distance Learning, v.12, n.2, 2011. Available from: <http:// www.irrodl.org/index.php/irrodl/article /view/791/1699>. Cited: May 19, 2014.

Pepper, S. The TAO of topic maps: Finding the way in the age of infoglut. 2002. Available from: <http://www.ontopia.net/ topicmaps/materials/tao.html>. Cited: May 19, 2014.

Pieri, M.; Diamantini, D. From e-learning to mobile learning: New opportunities. 2009. Available from: <http://www. aupress.ca/books/120155/ebook/09_Mohamed_Ally_2009Article9.pdf>. Cited: May 19, 2014.

Prensky, M. What can you learn from a cell phone? Almost anything!, 2004. Available from: <http://thinkingmachine. pbworks.com/f/Prensky-What_Can_You_Learn_From_ a_Cell_Phone-FINAL.pdf>. Cited: May 19, 2014.

Quinn, C.N. Mobile learning: Landscape and trends. Santa Rosa: Temple Smolen M.B.A, 2011.

Raso, P. Definire gli obiettivi didattici. 2007. Available from: $<$ blog.edidablog.it/files/File/.../Obiettivi\%20didattici(1).doc>. Cited: May 19, 2014.

Sharples, M. et al. The design and implementation of a mobile learning. Journal Personal and Ubiquitus Computing, v.6, n.3, p.220-234, 2002.

Shneiderman, B.; Plaisants, C. Designing the user interface: Strategies for effective human-computer interaction. San Francisco: Addison Wesley, 2009.

Siemens, G. Connectivism: A learning theory for the digital age, 2004. Availabre from: <http://www.ingedewaard.net/papers/ connectivism/2005_siemens_ALearningTheoryForThe Digital Age.pdf $><$ http://es.scribd.com/doc/201419/Conectivismouna-teoria-del-aprendizaje-para-la-era-digital> Cited:May 19, 2014. 
Stead, G. Towards open Formats for mobile learning. In: World Conference on Mobile and Contextual Learning, 11., Helsinki, 2012. Available from: <https://wss.apan.org/jko/mole/ Shared\%20Documents/Towards\%20open\%20formats \%20for\%20Mobile\%20Learning.pdf>. Cited: May 19, 2014.

Stracke, M. Quality development and standards in learning, education, and training: Adaptation model and guidelines for implementations. Informatika, v.7, n.3, 2010. Available from: $<$ http://www.qed-info.de/docs/Quality_Development_and_ Standards_in_LET_Stracke_Informika_2010.pdf >.Cited: May 19, 2014.

Torres Toro, S.; Carrillo Ortega, J. Indicadores de calidad en las plataformas de formación virtual: una aproximación sistemática.Etic@net,v.1, 2003. Disponible en: <http:// www.ugr.es/ sevimeco/revistaeticanet/Numero1/Articulos/ Calidade.pdf>. Acceso en: 19 mayo 2014.

Traxler, J. Defining, discussing, and evaluating mobile learning: The moving finger writes and having wri. International Review of Research in Open and Distance Learning, v.8, n.2, p.1-12, 2007.

Vidal, C.; Segura, A.; Prieto, M. Calidad en objetos de aprendizaje. In: Simposio Pluridisciplinar sobre Diseño y Evaluación de Contenidos Educativos Reutilizables, 5., 2008. Actas... Salamanca: Universidad de Salamanca. Disponible en: <www. web.upsa.es/spdece08/contribuciones/139_CalidadEn ObjetosDeAprendizajeTypelnstSpringerFinalVidalSegura Prietov99.pdf>. Acceso en: 19 may 2014.

Vivanet, G. Progettazione lógico-concettuale di percorsi e contenuti didattici: proposta di un modelo. 2009. Tesis (Doctoral) - Universitá degli Studi di Genova, 2009. Disponibili in: <www.elearninglab.eu/publications/TESI_DOTTORATO. pdf>. Accesso: 19 magg. 2014.

West, D. Digital schools: How technology can transform education. Washington: Brookings Institution Press, 2012 
